\title{
Patient Reflections: Saying Good-Bye to a Retiring Family Doctor
}

Beth Merenstein, PhD, and Joel Merenstein, $M D$

Purpose: The purpose of this study was to describe the doctor-patient relationship as expressed in written comments to a retiring family physician.

Methods: All 200 of the written notes and e-mails to a single family physician retiring after 42 years in practice were examined using content analysis for general themes and meaning. No phone or personal verbal responses were included.

Results: Seven themes emerged with regards to what patients appreciated in their family physician relationship. These included "being there," caring, medical expertise, personal characteristics, multiple roles/anything goes, family, and continuity.

Conclusion: Analyzing comments from actual patients at the end of a long-term relationship with an individual physician confirms beliefs of what patients consider important based on theoretical models, surveys, and interviews. (J Am Board Fam Med 2008;21:461-465.)

A positive doctor-patient relationship can have an improved health impact ${ }^{1}$ and the lack of one causes deterioration in patient care. ${ }^{2,3}$ Using surveys, interviews, or focus groups, several studies have gone directly to patients asking specifically, What do people want from their family physician? ${ }^{4-6}$ Models proposed include the biopsychosocial model, ${ }^{7}$ patient-centered care, ${ }^{8}$ and the narrative method. ${ }^{9}$ Other aspects of a positive doctor-patient relationship include empathy ${ }^{10}$ and continuity of care. ${ }^{11}$ However, no studies have reported on patients' real-life appreciation of their doctor after a longterm relationship. We sought to confirm and extend these theoretical or partial findings by reviewing and analyzing the spontaneous thank you notes written to a family physician at the time of his retirement. We focused on the question, What are the core attributes that patients select when choos-

This article was externally peer reviewed.

Submitted 10 August 2007; revised 20 December 2007; accepted 21 December 2007.

From the Department of Sociology, Central Connecticut State University, New Britain, CT (BM); and the Department of Medicine, University of Pittsburgh School of Medicine, PA (JM).

Funding: none.

Conflict of interest: Dr. Joel Merenstein is the retiring physician referred to in this article.

Corresponding author: Beth Merenstein, $\mathrm{PhD}$, Assistant Professor of Sociology, Central Connecticut State University, 1615 Stanley St., PO Box 4010, New Britain, CT 06050 (E-mail: merensteinb@ccsu.edu). ing to remember their family doctor? By analyzing patient letters, e-mails, and cards to a family physician retiring after 42 years in practice, we thought we would be able to get a true sense of the qualities patients found important in their relationship with their family doctor. We also felt that this information, based on patients' actual experiences and unsolicited feelings, would provide a more valid description than findings based on the conjecture of interviews or focus groups.

\section{Methods \\ Setting}

The practice was located in the eastern suburbs of a major city and the area included rural farm and coal mining communities before the city grew out to encompass it. The patients were mainly white middle class, with a mixture of those moving in to raise their families and those remaining from the small communities around the farms and coal mines. At this time there were 6 family physicians in a group practice, all doing hospital work but only one doing obstetrics. Three of the physicians, including one of the authors (BM), also had faculty positions at the largest family practice residency in the metropolitan area.

\section{Process}

This physician sent a letter to all his ongoing patients approximately 3 months before retirement, thanking 
Table 1. Themes and Representative Quotes Culled from Patient Correspondence

\begin{tabular}{|c|c|}
\hline Theme & Quotes \\
\hline 1. Being there & $\begin{array}{l}\text { - "Always being available for listening or discussion far beyond our medical needs." } \\
\text { - "It will take me a long time for me to get used to the fact that I can't just pick up } \\
\text { the phone and take advantage of your expertise when I need medical or personal } \\
\text { advice." } \\
\text { "You always had time for us no matter what you were doing for yourself." }\end{array}$ \\
\hline 2. Caring & $\begin{array}{l}\text { " "[You had] an amazing career as a compassionate and caring doctor, the best } \\
\text { healing medicine can provide." } \\
\text { - "Thank you for your great medical care and loving care." }\end{array}$ \\
\hline 3. Medical expertise & $\begin{array}{l}\text { "I have trusted your judgment about my medical needs and have been comfortable } \\
\text { with your way of thinking." } \\
\text { - "No matter what the wisdom of the specialist, it just wasn't true until we heard it } \\
\text { from you." }\end{array}$ \\
\hline 4. Personal characteristics & $\begin{array}{l}\text { "Taking the time to listen prior to any judgment." } \\
\text { "You made us feel like we were the most important people in the world." }\end{array}$ \\
\hline 5. Multiple roles/anything goes & - "You have been our healer, helper in sad times, and always our friend." \\
\hline 6. Family doctor & $\begin{array}{l}\text { - "It's like saying good bye to a member of the family." } \\
\text { - "You cared for my health and you understood my family." } \\
\text { - "You knew us far beyond our medical needs." }\end{array}$ \\
\hline 7. Continuity & $\begin{array}{l}\text { - "You have been my friend and healer most of my life." } \\
\text { - "Expressing my deepest appreciation to you...for the kindness and patience you } \\
\text { have shown my family for the past } 43 \text { years." } \\
\text { " My friend and my healer most of my life." }\end{array}$ \\
\hline
\end{tabular}

them for their trust and confidence and offering help for their future medical care. A majority of patients responded with a last visit or call. In addition there were 200 notes, letters, e-mails, and general correspondence.

\section{Analysis}

We used content analysis to search for meaning in the correspondence. We did not record or analyze the multiple in-person or phone verbal responses. Using the written correspondence, an independent transcriptionist typed into one master list every word verbatim, with no identifying source. Because the correspondence was obviously positive, this constituted a selective sample consistent with qualitative research methodology. ${ }^{12}$ Our intention here was not to simply reiterate what patients expressed to their long-term doctor but to focus on what longevity and continuity seemed to mean to patients. We made no effort to obtain any demographic information about the correspondents because that information would not add to our purpose. The University of Pittsburgh Institutional Review Board gave approval for this as an exempt study.
Both authors independently reviewed the typed comments. We separately highlighted important themes and, after multiple comparative reviews and repeat discussions, developed a single set of agreedupon themes.

\section{Biases of Investigators}

Biases to these notes included the personal involvement of both authors and a philosophy of practice that included the balance between scientifically sound medicine and the Balint principle: the desire by the physician to be perceived positively and even loved by these people and sadness and guilt at leaving them; "that by far the most frequently used drug in general practice was the doctor himself."13 Although it affected us personally we believe the analysis and interpretation were not influenced by our biases.

\section{Results}

We identified 7 overlapping themes. Each of these themes refered back to the general, overall question: What are the core attributes that patients refer to when remembering their family doctor? Themes and representative quotes are listed in Table 1. Although 
there is some overlap in these themes they can be meaningfully discussed separately.

\section{Theme 1: "Being There"}

The concept of "being there" is a state of mind, a belief system, a sense of trust, although not literally meaning being there every moment. ${ }^{14}$ As Loxterkamp asserts, "we must return to what has been our greatest asset-the relationships that flow from practice." 14 Overall, patients believe that the physician is available and accessible when they need him. Furthermore, patients believe the physician will recognize their needs and be able and willing to help even when there is not a cure or a solution to the problem.

Patients here expressed this in their remembrances of house calls in a time of need from many years past; in the consistency of having phone calls promptly returned; and always being available for listening and discussion. It is not so much that the physician must be there at all times, but that the patient has the sense that the physician is available when necessary. Simply knowing this can result in increased quality of care in terms of how the patient views the doctor. ${ }^{14}$

\section{Theme 2: Caring}

A second and equally important idea to the level of importance of the doctor to patients has to do with the very general yet crucial concept of "caring." Caring summarizes many aspects of the good doctorpatient relationship and is most eloquently described in Peabody's 1927 article. ${ }^{15}$ Caring or care in some form was the most common word mentioned in all of the patient communications. Patients also used other words that we interpreted as expressing a similar view, such as "gentle counsel," "personal devotion," "compassion," and "loving care." At other times, the use of these words in context informs us that the patients were not always referring to the actual medical care provided by the physician, but were often signifying an overall level of care and concern for them as a whole person or family unit.

\section{Theme 3: Medical Expertise}

We would be remiss if we did not acknowledge that many patients wanted medical wisdom. This included various components: they were pleased with the amount of knowledge they felt their doctor had, they appreciated being referred to a specialist when necessary, and they valued that the doctor ex- plained medical issues to them in such a way that was manageable and clear.

Although there is skepticism within the medical system, particularly in academic centers, that there can be one physician who provides comprehensive care for a broad range of health care problems and remain competent and current, patients generally accept that their own family physician knows and practices a high quality of medicine. ${ }^{16}$ Similarly, we found that, although very few patients mentioned specific medical expertise, many patients noted knowledge, medical skills, and conservative approaches to medical concerns as factors they appreciated.

\section{Theme 4: Personal Characteristics of a Family Physician}

There are many characteristics that patients think are unique or at least special to their own personal physician. This may be based on a coincidental match or an active selection based on trial and error by patients. In either case there is some need for the doctor and patient to like each other and certainly more important for the patient to feel that way. Some of the attributes patients here admired in this doctor were patience, gentleness, calmness, good cheer, kindness, and reassurance. In many ways, patients in this practice expressed pleasure that this doctor respected, informed, and involved them in their own decision making. Patients in this practice recognized and appreciated both the verbal (eg, responding in an encouraging way) and the nonverbal (smiling, nodding, etc) mannerisms of this physician.

\section{Theme 5: Multiple Roles/Anything Goes}

The classic or mythical old time country doctor served many functions in the community not limited to traditional doctoring. ${ }^{17,18}$ Patients often see it as a compliment to tell their family doctor "you are more than a doctor to me." Often, patients feel they receive a lack of personal attention from their physician; this is related to the sense that the physician is not "giving" enough to the patient. As one British study noted, patients are looking for whole person care. ${ }^{6}$ Patients want physicians who know about them and their family, as well as those who deal with the "whole person" in the entire context of their life and illness, not just centering on the illness itself. ${ }^{6}$ This was a common theme among the patients in this practice; they consistently used such terms as friend, advisor, guide, mentor, and 
"helped me make the right decision even when not medical." The word friend was used repeatedly by patients, although some physicians believe that a level of professional distance should be maintained between themselves and their patients. ${ }^{3}$ Patients in this practice felt connected and reassured by their physician precisely because he did not maintain an excessive level of professional distance and they could discuss anything with him.

\section{Theme 6: Family}

Family doctor implies not only caring for families as well as individuals but also being perceived as members of the patients' families. Patients responded to this total care by desiring not only the whole person care mentioned previously, but by desiring care for the entire family. Patients even traveled some distance to be seen by the same physician who had treated them as a child, treated their parents, siblings, and now, perhaps, their own children. Numerous patients told stories of how the physician treated their mother and was there when she died, and who now, at the time of retirement, was treating their child. Generational care is a component of continuity of care existing within the family-doctor relationship.

Patients here repeatedly noted that the physician took care of the entire family, as well as expressing concern for the caregivers. Many wrote that they perceived the doctor as an actual member of the family.

\section{Theme 7: Continuity}

Connected to this idea of total family care is the idea of continuity of care. This remains one of the major tenets of family medicine or primary care. Having a physician that knows you and your family and has shared with you important life events, happy and tragic, is a powerful force on the doctor-patient relationship that patients recognize. ${ }^{19}$ As Mainous et al explain, ${ }^{20}$ it is the interaction between the continuity of care and the experiences between the physician and patient that matter the most. Therefore, the longevity discussed here must be considered with regards to the previous discussions of characteristics expressed by the physician and the overall quality of the care. Although this may be more obvious in small rural towns where patients and physicians share many roles and activities, it is a necessary part of all family practices. ${ }^{17}$ In this practice numerous patients began their note by calling attention to the longevity of the relationship, noting that they had been a patient for more than 40 years, that 4 generations of their family were patients, or that they and the doctor had grown old together. What was also notable is how patients could recounting the exact number of years they had been a patient of this doctor. They were able to be specific because the years mattered. Additionally, what was significant about the years they remembered were details of events that had occurred to them as a patient, or to a family member who was a patient, from years ago. One woman wrote that, as she read of the retirement, she began to reminisce and recalled the very first house call this physician made to her house to see her father. As she noted later in her letter, that house call was more than 40 years ago. It is this interaction, between the bond of the relationship and the longevity of the relationship, that patients expressed over and over. Clearly this is important to patients, a quality they look for and hope to receive from their family doctor.

\section{Discussion}

Recently, the British Medical fournal asked the question of its readers, What's a good doctor and how do you make one? ${ }^{21}$ The answers received were varied, but consistently touched on many of the issues we have discussed above. Letters to the editors wrote of doctors who are good companions to patients, who are compassionate and caring, understanding, and show empathy. Not surprisingly, another article asking a similar question provided 7 ideal physician behaviors as expressed by patients: confident, empathetic, humane, personal, forthright, respectful, and thorough. ${ }^{22}$ The letters, notes, cards, and e-mails this doctor received validates these survey findings. Based on the qualitative responses here, patients value all these things; most particularly, they are searching for a bond with their doctor. They are responsive to, and desiring a relationship with, a physician who cares not only for their illness, but for them as a whole person and for their extended family as well.

We do not believe any of these themes are new but, based on actual comments from patients involved in a long-term relationship with their doctor, they provide richness and validation not available from surveys or focus groups. The authors were specifically concerned with what patients found positive at the end of a long-term relationship with a single physician. 
This study informs us that patients are seeking strong personal relationships with their family physician. Most of the themes are consistent with those found in other studies; in particular, researchers have found that, above all, patients want family physicians who "care," and who provide them with some level of continuity. ${ }^{23}$ To the patient, this means taking the time to listen to their concerns, making an effort to respond to their needs, and providing more than just medicine or prescriptions to those who come through the door. "To write prescriptions is easy but to come to an understanding with people is hard." 24 This can be rewarding for the physician as well. Furthermore, we know from this research and previous studies that this positive relationship leads to better overall health care for the patient.

In this age of searching for a new model of care ${ }^{25}$ with an emphasis on computers and guidelines, there remain enduring aspects of the doctor-patient relationship that are important to patients and which they are comfortable expressing. Transforming family medicine may be necessary but holding on to what has been proven to be important should be retained. Patients care.

The authors would like to thank Paula Preisach for the organization and management of this project; Bob Arnold, MD, Jack Coulehan, MD, and Will Miller, MD, for review and useful suggestions of earlier versions; and all of the patients for contributing their ideas.

\section{References}

1. Lutfey K. On practices of 'good doctoring': reconsidering the relationship between provider roles and patient adherence. Sociol Health Illn 2005;27:42147.

2. Murphy J, Chang H, Montgomery J, Rogers W, Gelb Safran D. The quality of physician-patient relationships. J Fam Pract 2001;50:123-9.

3. Rousseau PC. Social invitations, time constraints, and professional distance. Am J Hosp Palliat Care 2004;21:17-8.

4. American Academy of Family Physicians. Graham Center One-Pager. What people want from their family physician. Available from www.aafp.org/afp/ 20040515/graham1.html. Accessed 18 October 2006.

5. Scherger Joseph E. What patients want. J Fam Pract 2001;50:137.

6. Tarrant Windridge K, Boulton M, Baker R, Freeman G. Qualitative study of the meaning of personal care in general practice. BMJ 2003;326:1310-4.
7. Engel GL. Enduring attributes of medicine relevant of the education of the physician. Ann Intern Med 1973;78:587-93.

8. Levenstein JH, McCracken EC, McWhinney IR, Stewart MA, Brown JB. The patient-centered clinical method. 1. A model for the doctor-patient interaction in family medicine. Fam Pract 1986;3:24-30.

9. Charon R. Narrative medicine: a model for empathy, reflection, profession, and trust. JAMA 2001;286: 1897-902.

10. Larson EB, Yao X. Clinical empathy as emotional labor in the patient-physician relationship. JAMA 2005;293:1100-6.

11. Saultz JW, Albedaiwi W. Interpersonal continuity of care and patient satisfaction: a critical review. Ann Fam Med 2004;2:445-51.

12. Kuzel AJ. Sampling in qualitative inquiry. In: Crabtree BJ, Miller WL, eds. Doing qualitative research, 2nd ed. Thousand Oaks (CA); Sage Publications; 1999:33-45.

13. Balint $M$. The doctor, his patient and the illness, 2nd ed. New York: International Universities Press, Inc.; 1973:1.

14. Loxterkamp D. Being there: on the place of the family physician. J Am Board Fam Pract 1991;4: 354-60.

15. Peabody FW. The care of the patient. JAMA 1927; 88:877-82.

16. Chang JT, Hay RD, Shekelle PG, et al. Patients' global ratings of their health care are not associated with the technical quality of their care. Ann Intern Med 2006;144:665-72.

17. Rabinowitz HK. Caring for the country: family doctors in small rural towns. New York: Springer-Verlag; 2004.

18. Berger J, Mohr J. A fortunate man: the story of a country doctor. New York: Vintage; 1997.

19. Merenstein JH. My first patient. J Fam Pract 2002; 51:777.

20. Mainous A, Goodwin M, Stange K. Patient-physician shared experiences and value patients place on continuity of care. Ann Fam Med 2004;2:452-4.

21. Rizo CA, Jadad AR, Enkin M, et al. What's a good doctor and how do you make one? Doctors should be good companions for people. BMJ 2002;325:711.

22. Bendapudi NM, Berry LL, Frey KA, Parish JT, Rayburn WL. Patient's perspectives on ideal physician behaviors. Mayo Clin Proc 2006;81:338-44.

23. Get better care from your doctor. Consumer Reports 2007;32-6.

24. Kafka F. A country doctor. Available from http:// www.mala.bc.ca/ johnstoi/kafka/countrydoctor.htm. Accessed February 2008.

25. Martin JC, Avant RF, Bowman MA, et al. The Future of Family Medicine: a collaborative project of the family medicine community. Ann Fam Med 2004;2(Suppl 1):S3-S32. 